\title{
Whole-Body L-Leucine Oxidation in Patients with Variant Form of Maple Syrup Urine Disease
}

\author{
PETER SCHADEWALDT, ANNETTE BODNER-LEIDECKER, HANS-WERNER HAMMEN, \\ AND UDO WENDEL \\ Deutsches Diabetes Forschungsinstitut [P.S., A.B.-L., H.-W.H.] and Kinderklinik [H.-W.H., U.W.], \\ Heinrich-Heine-Universität Düsseldorf, Düsseldorf, Germany
}

\begin{abstract}
ABST
Whole-body L-leucine oxidation was assessed in patients with
maple syrup urine disease of different severity using oral L-[1-
$\left.{ }^{13} \mathrm{C}\right]$ leucine bolus tests ( $38 \mu \mathrm{mol} / \mathrm{kg}$ body weight). Residual
whole-body L-leucine oxidation was estimated on the basis of the
3 -h kinetics of ${ }^{13} \mathrm{CO}_{2}$ exhalation and ${ }^{13} \mathrm{C}$-isotopic enrichment in
plasma 4 -methyl-2-oxopentanoate using a noncompartmental
mathematical approach. In four patients with classical maple
syrup urine disease (two females and two males; mean age, $13 \pm$
5 y; range, $7-17$ y), L-leucine oxidation was too low to be
measurable. In two females (aged 11 and 15 y) with a severe
variant form of the disease, whole-body L-leucine oxidation was
reduced to about $4 \%$ of control. In six milder variants (two
females and four males; mean age $\pm \mathrm{SD}, 15 \pm 10 \mathrm{y}$; range, $6-34$
y), the estimates for residual whole-body L-leucine oxidation
ranged from 19 to $86 \%$ (59 $\pm 24 \%$ of control and were
substantially higher than the residual branched-chain 2 -oxo acid
\end{abstract}
dehydrogenase complex activities in the patients' fibroblasts (10-25\% of control). Possible mechanisms are considered that might contribute to a comparatively high residual in vivo Lleucine oxidation in (mild) variant maple syrup urine disease.

(Pediatr Res 49: 627-635, 2001)

Abbreviations:
APE, atom percent ${ }^{13} \mathrm{C}$-label enrichment
BCAA, branched-chain L-amino acids
BCOA, branched-chain 2-oxo acids
BCOA-DH, branched-chain 2-oxo acid dehydrogenase
complex
KIC, 4-methyl-2-oxopentanoate ( $\alpha$-ketoisocaproate)
MPE, mole percent ${ }^{13}$ C-label enrichment
MSUD, maple syrup urine disease
WBLO, whole-body L-leucine oxidation

MSUD [McKusik 248600/-10/-11 (1)] is a genotypically and phenotypically heterogenous inborn error of metabolism. In this disease, the degradation of BCAA is impaired due to a deficiency in BCOA-DH (EC 1.2.4.4) activity. Accumulation of BCAA and the corresponding 2-oxo acids can exert neurotoxic effects by as yet unknown mechanisms. The current therapy primarily relies on a life-long reduction of BCAA in the diet (2).

The clinical severity of the disease ranges from severe classical to mild variant forms. Classification of the patients is based on indirect parameters such as time of onset, L-leucine tolerance, and residual BCOA-DH activity as determined in the patients' skin fibroblasts (2). In addition, there are reports on so-called thiamine-responsive patients $(2,3)$. The existence of

Received June 5, 2000; accepted December 19, 2000.

Correspondence: Dr. Peter Schadewaldt, Deutsches Diabetes Forschungsinstitut, Klinische Biochemie, Auf'm Hennekamp 65, D-40225 Düsseldorf, Germany; e-mail: schadewa@uni-duesseldorf.de

This work was supported in part by Grant We 614/9-3 from Deutsche Forschungsgemeinscheft.

Some preliminary results have been presented at the 1999 annual meetings of the Arbeitsgemeinschaft Pädiatrische Stoffwechselstörungen (APS), Fulda, Germany, and of the Society for the Study of Inborn Errors of Metabolism (SSIEM), Genoa, Italy. this form of MSUD, however, has never been proven convincingly.

In general, the correlation between the clinical severity in patients and the residual activity of the enzyme complex in the patients' cells is unsatisfactory. For a rational classification of the patients and for reliable assessment of therapeutic interventions, e.g. thiamine therapy, determination of the severity of the disease in vivo is necessary.

The method of choice for characterizing patients with MSUD is measurement of their L-leucine oxidation. A few studies have been published using the primed continuous infusion approach and isotopically labeled L-leucine as substrate for investigation of WBLO in classical MSUD. However, contradictory results were obtained. Whereas some patients failed to exhibit a measurable WBLO, more than one half of the subjects had clearly measurable L-leucine oxidation rates ranging from 8 to $40 \%$ of control (4-7). Elsas and colleagues (8) suggested a noninvasive ${ }^{13} \mathrm{CO}_{2}$ breath test with oral application of $\mathrm{L}-\left[1-{ }^{13} \mathrm{C}\right]$ leucine for in vivo studies in classical and variant MSUD. The assessment of (residual) WBLO in MSUD by ${ }^{13} \mathrm{CO}_{2}$ breath tests is unsatisfactory because of the expanded and variable body pools of L-leucine and KIC. These cause a 
generally higher, but apparently unpredictable, dilution of the administered ${ }^{13} \mathrm{C}$-label than in healthy subjects $(9,10)$.

In a recent study, we discussed the application of an invasive $\mathrm{L}-\left[1-{ }^{13} \mathrm{C}\right]$ leucine loading test in healthy subjects and classical MSUD patients (10). In conjunction with a stabilization of BCAA plasma concentrations by dietary means, this experimental approach was applied to the assessment of residual WBLO in patients with MSUD of different clinical severity.

\section{MATERIALS AND METHODS}

Materials. Unless otherwise noted, all chemicals were purchased in the highest available purity from Merck (Darmstadt, Germany) or Sigma Chemie (Munich, Germany). Glucose solution (100 g/L) was from B. Braun (Melsungen, Germany). L- $\left[1-{ }^{13} \mathrm{C}\right]$ Leucine was supplied by Promochem (Wesel, Germany). Purity and isotope enrichment as analyzed by automatic amino acid analysis and gas chromatography-mass spectrometry was as specified by the supplier.

Subjects. Patients (classical MSUD, $n=4$; variant forms, $n$ $=8$ ) originating from several European countries (Austria, France, Germany, Spain, and Turkey) participated in the study. With the exception of the genetic defect, all subjects had a normal physical examination and none of them received medication or had an additional acute or chronic illness. Characteristic data of the patients are compiled in Table $1(11,12)$. The initial plasma concentrations of branched-chain compounds before the oral L- $\left[1-{ }^{13} \mathrm{C}\right]$ leucine loads are presented in Table 2. Five healthy volunteers - one woman and four men, age $[$ mean $\pm \mathrm{SD}$ (range)], $30 \pm 11$ y (24-50 y); weight, $67 \pm$ $9 \mathrm{~kg}(58-80 \mathrm{~kg})$; and height, $175 \pm 6 \mathrm{~cm}(169-181 \mathrm{~cm})$ served as controls.

This study was approved by the Ethikkommission of the Heinrich-Heine-Universität Düsseldorf, and written informed consent was obtained from all subjects (or their parents) before entering the study.
Loading tests. Oral loading tests with $\mathrm{L}-\left[1-{ }^{13} \mathrm{C}\right]$ leucine $[99 \%$ $1-{ }^{13} \mathrm{C}, 38 \mu \mathrm{mol} / \mathrm{kg}$ body weight (wt)] were performed under resting conditions, essentially as previously described (10). In short, patients and controls received the loading dose dissolved in diluted citric acid (5 mM) between 0900 and $0930 \mathrm{~h}$. Samples of venous EDTA blood and expired air were collected before (basal values) and for a period of $3 \mathrm{~h}$ after the load according to the time schedule depicted in Figure $3(0-45 \mathrm{~min}$, every $5 \mathrm{~min}$; $45-60 \mathrm{~min}$, every $7.5 \mathrm{~min}$; 60-180 $\mathrm{min}$, every 15 $\min )$.

Unless otherwise noted, the subjects ingested two additional standardized meals at $2200 \mathrm{~h}$ and $0700 \mathrm{~h}$ before the load. The high-carbohydrate, low-protein meals consisted of cookies [1 $\mathrm{g} / \mathrm{kg}$ body wt, $23.6 \mathrm{~kJ} / \mathrm{kg}$ body wt; Walliser Plätzchen [65.5\% carbohydrate, $33 \%$ fat, $0.1 \%$ protein (equivalent to $0.07 \mathrm{mg}$ L-leucine/kg body wt); a gift from Scientific Hospital Supply (Heilbronn, Germany)]; and $100 \mathrm{~mL}$ mineral water. According to analyses performed by Dr. Förstel, FZ Jülich, Germany, the cookies contained $46.1 \% \mathrm{C}$, the ${ }^{13} \mathrm{C} /{ }^{12} \mathrm{C}$-ratio was -22.9 $\delta$-values.

Analytical procedures. Procedures for the quantitation of BCAA and BCOA in plasma samples have been previously described in detail (13). ${ }^{13} \mathrm{CO}_{2}$ content in the expired air was determined using isotope ratio mass spectrometry. Total $\mathrm{CO}_{2}$ output was measured by indirect calorimetry (Datex Deltatrac, Datex Instruments, Helsinki, Finland).

For the estimation of ${ }^{13} \mathrm{C}$-enrichment in plasma L-leucine, plasma $(0.5 \mathrm{~mL})$ was deproteinized by mixing with an equal volume of 5-sulfosalicylic acid (100 g/L) and centrifugation $\left(10,000 \times g, 10 \mathrm{~min}, 4^{\circ} \mathrm{C}\right)$. The supernatant $(0.5 \mathrm{~mL})$ was applied onto a Dowex 50 WX 8-column (200-400 mesh, $\mathrm{H}^{+}$-form, $\left.0.5 \mathrm{~mL}\right)$. After washing with $\mathrm{H}_{2} \mathrm{O}(2 \mathrm{~mL})$, the L-amino acids were eluted from the column using $\mathrm{NH}_{4} \mathrm{OH}(2$ $\mathrm{M}, 1.2 \mathrm{~mL})$. After evaporation to dryness, the residue was treated with $N$-methyl-N-(t-butyldimethylsilyl)-trifluoroacet-

Table 1. Clinical characteristics of MSUD patients undergoing oral $L-\left[1-{ }^{13} \mathrm{C}\right]$ leucine loads

\begin{tabular}{|c|c|c|c|c|}
\hline Patient & $\begin{array}{l}\text { Age*, } \\
\text { (years) }\end{array}$ & $\begin{array}{l}\text { Weight* } \\
\text { (kg) }\end{array}$ & $\begin{array}{l}\text { Height* } \\
\text { (cm) }\end{array}$ & $\begin{array}{l}\text { Protein intake } \$ \\
\text { (g/d per kg body wt) }\end{array}$ \\
\hline \multicolumn{5}{|l|}{ Classical MSUD } \\
\hline L.S. (female) & $7(3 d)$ & 24 & 121 & 0.3 \\
\hline M.M. (male) & $16(13 d)$ & 75 & 168 & 0.2 \\
\hline L.G. (female) & $17(12 \mathrm{~d})$ & 65 & 166 & 0.2 \\
\hline \multicolumn{5}{|l|}{ Variant MSUD } \\
\hline L.F. $\|$ (female) & 8 (3 wk) & 25 & 123 & $1.0-1.5$ \\
\hline F.U.\| (female) & $11(1 \mathrm{wk})$ & 37 & 141 & 0.2 \\
\hline H.H.ๆ (male) & $13(7.5 \mathrm{y})$ & 43 & 160 & $0.8-1.2(9)$ \\
\hline R.R.\| (female) & $15(8 d)$ & 49 & 151 & 0.3 \\
\hline D.N. (male) & 19 (4 wk) & 59 & 181 & $1.5(25)$ \\
\hline S.T. (male) & $34(3.2 \mathrm{y})$ & 75 & 183 & $0.6-1.0(15)$ \\
\hline
\end{tabular}

* At the (first) loading test.

$\dagger$ In parentheses: age at diagnosis.

$\$$ Recommended dietary intake.

$\S$ In parentheses: residual L-leucine oxidation in cultured skin fibroblasts according to 11 , percent of control.

$\|$ Clinically severe variants.

ๆ For additional patient data see 12. 
Table 2. Initial plasma concentrations of branched-chain compounds*

\begin{tabular}{|c|c|c|c|c|}
\hline \multirow[b]{2}{*}{ Patient } & \multicolumn{4}{|c|}{ Plasma concentration $\dagger(\mu \mathrm{M})$} \\
\hline & Leucine & Valine & Isoleucinet & Alloisoleucine \\
\hline \multicolumn{5}{|l|}{ Classical MSUD§ } \\
\hline G.S. & $191(116)$ & $87(10)$ & $15(34)$ & 85 \\
\hline M.M. & $195(101)$ & $118(13)$ & $111(87)$ & 63 \\
\hline L.G. & $506(392)$ & $187(38)$ & $111(124)$ & 60 \\
\hline P.H. & $196(146)$ & $230(38)$ & $85(82)$ & 24 \\
\hline L.F. & $562(396)$ & $624(92)$ & 207 (197) & 63 \\
\hline F.U. & $594(401)$ & $255(41)$ & $194(167)$ & 58 \\
\hline H.H. & $174(103)$ & $257(32)$ & $79(56)$ & 11 \\
\hline R.R. & $734(578)$ & $359(75)$ & $221(260)$ & 142 \\
\hline D.N.. & $545(272)$ & $551(85)$ & $151(103)$ & 34 \\
\hline
\end{tabular}

* Before the $\mathrm{L}-\left[1-{ }^{13} \mathrm{C}\right]$ leucine load.

$\dagger$ In parentheses: concentration of the corresponding 2-oxo acid.

$\$$ In parentheses: total 3-methyl-2-oxopentanoate (sum of $S$ - and $R$-enantiomorph).

$\S$ For nutritional state see "Results" section.

|| Subjects received standardized meals (cf. "Methods" section).

II Two loading tests (10/97 and 09/98).

amid (MTBSTFA, Pierce Chemicals, Rockford, IL, U.S.A.; 30 $\mu \mathrm{L}$ ) overnight to form the $\mathrm{N}, \mathrm{O}$-di-t-butylmethylsilyl (TBDMS) derivative of $\mathrm{L}-\left[{ }^{13} \mathrm{C}\right]$ leucine.

For the assessment of ${ }^{13} \mathrm{C}$-enrichment in plasma KIC, the quinoxaline derivative was prepared and purified by solid phase extraction as described previously (13). After evaporation to dryness, the residue was treated with MTBSTFA as described above to form the $O$-TBDMS $\left[{ }^{13} \mathrm{C}\right]$ quinoxalinol derivative.

The TBDMS derivatives were then subjected to gas chromatographic-mass spectrometric analysis on an HP 6890 gas chromatograph equipped with an HP-5-MS capillary column (5\% phenylmethylpolysiloxane, $30 \mathrm{~m}, 0.25$ - $\mathrm{mm}$ internal diameter, $0.25-\mu \mathrm{m}$ film thickness) directly coupled to an HP mass selective detector. Helium was used as carrier gas and a $1-\mu \mathrm{L}$ sample was injected in splitless mode. Injector and transfer line to the mass spectrometer were held at $250^{\circ} \mathrm{C}$. The column temperature was $100^{\circ} \mathrm{C}$ initially for $0.5 \mathrm{~min}$ and then raised to $260^{\circ} \mathrm{C}$ at $10^{\circ} \mathrm{C} / \mathrm{min}$ and at $20^{\circ} \mathrm{C} / \mathrm{min}$ for analysis of ${ }^{13} \mathrm{C}$ enrichment in L-leucine and KIC, respectively. Electron impact mode was applied. The ion source was operated at $70 \mathrm{eV}$ at $140^{\circ} \mathrm{C}$. For assessment of the ${ }^{13} \mathrm{C}$-enrichment in L-leucine and the corresponding 2-oxo acid, the ratio (R) of the ion intensities $\mathrm{m} / \mathrm{z} 303$ to $\mathrm{m} / \mathrm{z} 302$ and $\mathrm{m} / \mathrm{z} 260$ to $\mathrm{m} / \mathrm{z} 259$, respectively, was measured using selected ion monitoring.

Label enrichment. The MPE in metabolites was calculated from the natural abundance ratio as measured in the samples withdrawn before $\left(\mathrm{R}_{0}\right)$ and the values after $(\mathrm{R})$ oral administration of the ${ }^{13} \mathrm{C}$-labeled L-leucine according to Wolfe (14) as $\mathrm{MPE}=\left(\mathrm{R}-\mathrm{R}_{0}\right) /\left\{\mathrm{R}-\mathrm{R}_{0}\right)+1 \times 100$. Likewise, increase of ${ }^{13} \mathrm{C}$-label (APE) in expired $\mathrm{CO}_{2}$ was calculated as the difference of ${ }^{13} \mathrm{CO}_{2}$ in breath samples withdrawn before (control value) and after the oral loads. Rates of extra ${ }^{13} \mathrm{CO}_{2}$ exhalation were calculated from the APE on the basis of the total $\mathrm{CO}_{2}$ exhalation rate.

Estimation of residual in vivo leucine oxidation. For assessment of WBLO according to the reciprocal pool model (15), a noncompartmental calculation was derived from the steady-state approach as follows (cf. Fig. 1): WBLO can be expressed in terms of the appropriate (whole-body) rate constant $\mathrm{k}$ for oxidative decarboxylation of $\mathrm{KIC}$ and the amount of the 2-oxo acid (KIC), i.e. $\mathrm{WBLO}=\mathrm{k} \times \mathrm{KIC}$.

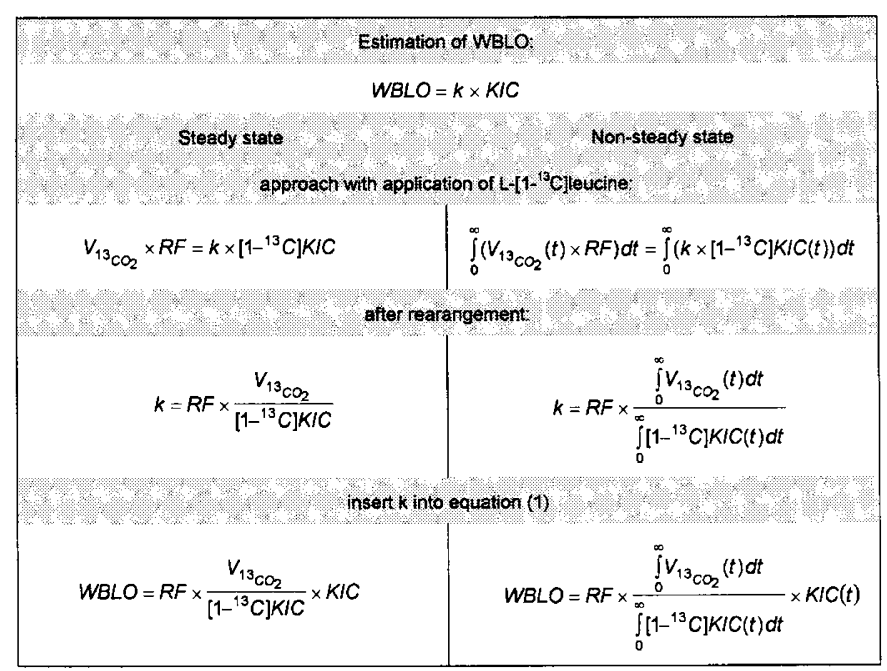

Figure 1. Comparison of steady-state and nonsteady-state calculations of whole body L-leucine oxidation in $\mathrm{L}-\left[1-{ }^{13} \mathrm{C}\right]$ leucine loading studies. $k$, whole body rate constant for KIC decarboxylation $\left(\mathrm{min}^{-1}\right)$; $\left[\mathrm{V}_{13 \mathrm{Co}_{2}}\right.$, whole-body ${ }^{13} \mathrm{CO}_{2}$ exhalation over basal $(\mu \mathrm{mol} / \mathrm{min}) ; R F$, correction factor for ${ }^{13} \mathrm{CO}_{2}$ retention; $\left[1-{ }^{13} \mathrm{C}\right] \mathrm{KIC}$, whole body amount of 4-methyl-2-oxo $\left[1-{ }^{13} \mathrm{C}\right]$ pentanoate $(\mu \mathrm{mol})$. 
Under steady-state conditions and use of $1-{ }^{13} \mathrm{C}$-labeled Lleucine, the rate of oxidative decarboxylation of $\left[1-{ }^{13} \mathrm{C}\right] \mathrm{KIC}(\mathrm{k}$ $\times\left[1-{ }^{13} \mathrm{C}\right] \mathrm{KIC}$ ) equals the rate of ${ }^{13} \mathrm{CO}_{2}$ formation (over basal). The latter is given by the rate of the experimentally measured rate of ${ }^{13} \mathrm{CO}_{2}$ exhalation $\left(\mathrm{V}_{13 \mathrm{CO}_{2}}\right)$ corrected for the portion of ${ }^{13} \mathrm{CO}_{2}$ not released from the body (RF, multiplier 1.1 (16)). Thus, WBLO can be expressed as

$$
\mathrm{WBLO}=\mathrm{RF} \times \frac{\mathrm{V}_{13 \mathrm{CO}_{2}}}{\left[1-{ }^{13} \mathrm{C}\right] \mathrm{KIC}} \times \mathrm{KIC}
$$

$\mathrm{V}_{13 \mathrm{CO}_{2}}$ (in exhaled air) and the ratio $\mathrm{KIC} /\left[1-{ }^{13} \mathrm{C}\right] \mathrm{KIC}$ (in plasma) are measured in the experiment and can be used for estimation of WBLO.

To account for the different labeling kinetics in $\mathrm{V}_{13 \mathrm{CO}_{2}}$ and $\left[1-{ }^{13} \mathrm{C}\right] \mathrm{KIC}$ under the present nonsteady-state conditions, these parameters were integrated over (infinite) time. The integrals are given by the areas under the respective kinetic curves [area under the curve (AUC)]. In analogy to the steady-state approach, WBLO was estimated by the formula

$$
\mathrm{WBLO}=\mathrm{RF} \times \frac{\mathrm{AUC}_{\mathrm{V}_{13 \mathrm{Bag}_{2}}}}{\mathrm{AUC}_{\left[1^{1-13} \mathrm{C}\right] \mathrm{KIC}}} \times \mathrm{KIC}
$$

No reliable information is available on the pool size of KIC (and hence $\left[1-{ }^{13} \mathrm{C}\right] \mathrm{KIC}$ ) in humans. Therefore, plasma concentrations were used for calculation. The rationale is as follows: Distribution volumes and metabolic rates of naturally labeled and $1-{ }^{13} \mathrm{C}$-labeled KIC are likely to be identical. Thus, we assume that any error that might arise from use of the $\left[1-{ }^{13} \mathrm{C}\right] \mathrm{KIC}$ plasma concentration in the denominator instead of the appropriate pool size, would (mathematically) be compensated by an equal error introduced by the use of total plasma $\mathrm{KIC}$ concentration in the numerator instead of the KIC pool size.

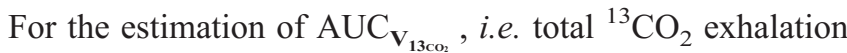
over basal, we used a recently established mathematical procedure (19). In short, the function

$$
y(t)=\sum_{i=1}^{4} a_{i} \times e^{-k_{i} \times t}
$$

where $y(t)$ is the extra ${ }^{13} \mathrm{CO}_{2}$ exhalation rate after load (in $\mu \mathrm{mol} / \mathrm{min}), \mathrm{a}_{\mathrm{i}}$ and $\mathrm{k}_{\mathrm{i}}$ are constants and $\mathrm{t}$ is the time after load (in min), was used to provide estimates for $\mathrm{a}_{\mathrm{i}}$ and $\mathrm{k}_{\mathrm{i}}$. For estimation of constants, the model was fitted to the experimental data by nonlinear regression analysis (as provided by the curve-fit procedure of Sigma Plot 2.0 from Jandel Scientific, Erkrath, Germany).

These estimates can then be used for calculation of the total extra ${ }^{13} \mathrm{CO}_{2}$ output $\mathrm{Y}(\mathrm{t} \infty)$ (in $\mu \mathrm{mol}$ ) applying the formula

$$
Y\left(t_{\infty}\right)=\sum_{i=1}^{4} a_{i} \times \frac{1}{k_{i}}
$$

which is derived from Eq. 2 by integration and extrapolation to infinite time.
Table 3. Parameters for the estimation of residual whole body L-leucine oxidation in patients with variant form of MSUD*

\begin{tabular}{lccc}
\hline \multirow{2}{*}{ Patient } & \multicolumn{2}{c}{ Area under curve† } & Plasma KIC $\ddagger$ \\
\cline { 2 - 3 } & $\mathrm{V}_{13 \mathrm{co}_{2}}$ & {$\left[1-{ }^{13} \mathrm{C}\right] \mathrm{KIC} \|$} & \\
\hline Variant MSUD & & & \\
M.S. & $0.86(0.999)$ & $1.08(0.925)$ & $85 \pm 8$ \\
P.H. & $2.81(0.983)$ & $2.26(0.949)$ & $147 \pm 7$ \\
L.F. & $3.34(0.966)$ & $5.91(0.952)$ & $374 \pm 11$ \\
F.U. & $0.20(0.622)$ & $5.61(0.956)$ & $390 \pm 7$ \\
H.H. & $3.82(0.983)$ & $1.03(0.833)$ & $87 \pm 8$ \\
R.R. & $0.17(0.790)$ & $7.43(0.967)$ & $585 \pm 12$ \\
D.N. & $3.31(0.993)$ & $3.47(0.894)$ & $302 \pm 13$ \\
S.T. & $4.25(0.971)$ & $1.76(0.994)$ & $115 \pm 5$ \\
Controls & $4.65(0.959)$ & $7.53(0.990)$ & $389 \pm 7$ \\
Mean $\pm \mathrm{SD}(n=5)$ & $6.77 \pm 1.58$ & $0.61 \pm 0.10$ & $33 \pm 4$ \\
& $(0.974 \pm 0.028)$ & $(0.942 \pm 0.031)$ & \\
\hline
\end{tabular}

* In tests with oral L-[1- $\left.{ }^{13} \mathrm{C}\right]$ leucine application $(38 \mu \mathrm{mol} / \mathrm{kg}$ body $\mathrm{wt})$. The subjects received standardized meals before load (cf. "Methods" section).

$\dagger$ Calculated on the basis of kinetics of the extra ${ }^{13} \mathrm{CO}_{2}$ exhalation rate $\left(\mathrm{V}_{13 \mathrm{CO}_{2}}\right)$ and plasma $1-{ }^{13} \mathrm{C}$-labeled 4-methyl-2-oxopentanoate $\left(\left[1-{ }^{13} \mathrm{C}\right] \mathrm{KIC}\right)$ as detailed in "Methods."

$\S$ In parentheses: coefficient of determination $\mathrm{R}^{2}$ of the fit of experimental data to the fit function (Eq. 2).

$\$$ Mean $\pm \mathrm{SD}(n=20)$ plasma concentration of 4-methyl-2-oxopentanoate during the 3-h experimental period.

$\|$ Area $\times 10^{-3}$.

I Two loading tests (10/97 and 09/98).

In analogy, the plasma kinetic of $\left[1-{ }^{13} \mathrm{C}\right] \mathrm{KIC}$, as calculated from the $1-{ }^{13} \mathrm{C}$-enrichments and the total plasma concentrations of the 2-oxo acid, was fitted to Eq. 2 and the resulting constant estimates then used to calculate the $\mathrm{AUC}_{\left[1-{ }^{13} \mathrm{C}\right] \mathrm{KIC}}$ according to Eq. 3. The means of the plasma concentration during the 3-h experimental period $(n=20, \mathrm{SD}<15 \%$ of mean) were used as estimates for KIC (cf. Table 3).

For comparison, WBLO were normalized to kilogram body weight. Residual WBLO in the patients (in percentage of control) are related to the mean value (control WBLO $\equiv$ $100 \%$ ) as calculated on the basis of Eq. 1 and the experimental data obtained in the five healthy volunteers. The values used for estimation of residual WBLO in individual patients are compiled in Table 3. Data on the maximal ${ }^{13} \mathrm{C}$-enrichment in plasma L-leucine and KIC were obtained by fitting procedures as detailed previously (10).

Statistics. Results are presented as means \pm SD, with the number of determinations in parentheses or as means as provided by the fit procedures. Cumulatives were obtained by trapezoidal methods. Linear regression (least squares method) was used for correlation analysis.

\section{RESULTS}

Pretest stabilization of plasma BCAA in MSUD. Our first MSUD patient [D.G., classical form (cf. 19)], showed an unexpected doubling of L-leucine in plasma (from 226 to 450 $\mu \mathrm{M}$ ) during an overnight fast. In a first attempt to counteract the fasting catabolism by supply of carbohydrate, two adult patients (L.G., M.M.) were hospitalized and received a continuous i.v. infusion of D-glucose ( $3 \mathrm{mg} / \mathrm{min}$ per $\mathrm{kg}$ body wt) from the late evening until the end of the experiment next morning. 


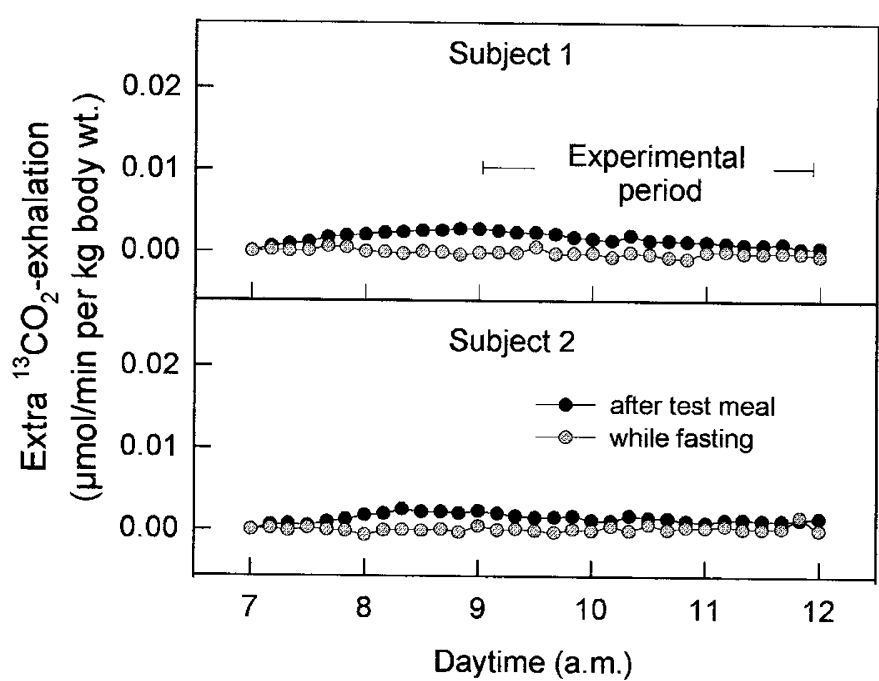

Figure 2. Extra ${ }^{13} \mathrm{CO}_{2}$ exhalation in healthy adult volunteers after ingestion of a standardized carbohydrate-rich, low-protein meal (see "Methods" for details). Control samples (basal values) were taken after an overnight fast ( $>10$ h) just before the meal at $0700 \mathrm{~h}$. From 0900 to $1200 \mathrm{~h}$ (the period generally assigned to $\mathrm{L}-\left[1-{ }^{13} \mathrm{C}\right]$ leucine loading tests as indicated), the meal-induced cumulative extra ${ }^{13} \mathrm{CO}_{2}$ exhalation amounted to 0.27 and $0.26 \mu \mathrm{mol} / \mathrm{kg}$ body wt in subjects 1 and 2, respectively. ${ }^{13} \mathrm{CO}_{2}$ exhalation remained essentially unchanged in the same subjects while fasting.

However, the plasma concentrations of L-leucine nevertheless nearly doubled in both patients overnight (cf. Table 2).

We then attempted a dual strategy. Additional carbohydraterich, low-protein meals ( $24 \mathrm{~kJ} / \mathrm{kg}$ body wt) were given in the late evening and early morning to reduce the physiologic fasting stress. The psychological stress was reduced by performing the investigation under familiar conditions (i.e. at the patient's pediatrician's office or at the patient's home, as desired, with attending pediatrician and parents present). These provisions successfully prevented the nocturnal increase of BCAA and BCOA (patients L.S., G.S.; cf. Table 2) and were well tolerated. Therefore, this treatment was used in subsequent studies on WBLO in variant MSUD.

Effect of the test meal on ${ }^{13} \mathrm{CO}_{2}$ exhalation. Compared with the normal ${ }^{13} \mathrm{C}$ content in exhaled $\mathrm{CO}_{2}$ (about $-26 \delta$-values), the standardized meal was enriched in ${ }^{13} \mathrm{C}(-22.9 \delta$-values $)$. Therefore, the effect of the meal on the ${ }^{13} \mathrm{CO}_{2}$ exhalation was checked in healthy adults (Fig. 2). Compared with postabsorptive conditions, there was a slight increase of ${ }^{13} \mathrm{CO}_{2}$ exhalation after ingestion of the meal, which gradually declined to basal levels during the period assigned to the $\mathrm{L}-\left[1-{ }^{13} \mathrm{C}\right]$ leucine loading tests.

Studies in healthy subjects. For establishment of control values, $\mathrm{L}-\left[1-{ }^{13} \mathrm{C}\right]$ leucine loads were performed postprandially in five healthy subjects (cf. Fig. 3). Within the 3-h test period, the cumulative extra ${ }^{13} \mathrm{CO}_{2}$ exhalation amounted to $5.48 \pm$ $1.37(4.40-8.18) \mu \mathrm{mol} / \mathrm{min}$ per $\mathrm{kg}$ body wt, equivalent to 14.4 $\pm 4.0 \%(11.6-21.5 \%)$ of the $\mathrm{L}-\left[1-{ }^{13} \mathrm{C}\right]$ leucine dose applied. The WBLO estimates amounted to $0.40 \pm 0.17$ (range, $0.31-$ 0.70) $\mu \mathrm{mol} / \mathrm{min}$ per kg body wt.

Findings in classical MSUD. Four patients with classical MSUD underwent the $\mathrm{L}-\left[1-{ }^{13} \mathrm{C}\right]$ leucine bolus test. One patient had clearly increased plasma L-leucine concentrations, and
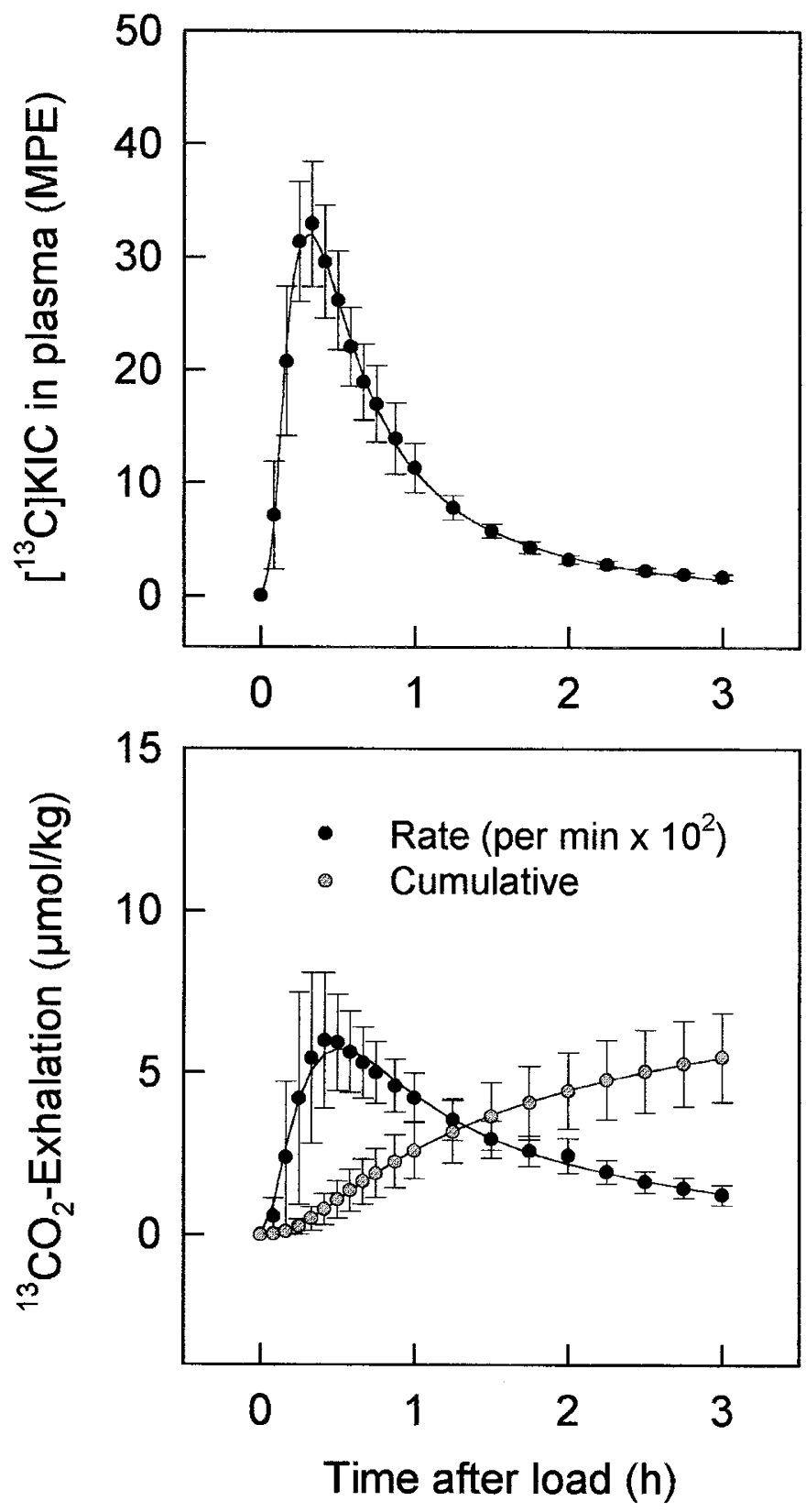

Figure 3. Time course of MPE in plasma KIC and ${ }^{13} \mathrm{CO}_{2}$ exhalation (over basal) in healthy subjects after an oral $\mathrm{L}-\left[1-{ }^{13} \mathrm{C}\right]$ leucine load $(38 \mu \mathrm{mol} / \mathrm{kg}$ body wt). Results are means \pm SD $(n=5)$.

three patients exhibited near normal plasma L-leucine concentrations (Table 2). The time course of concentration and ${ }^{13} \mathrm{C}$ enrichment of L-leucine and $\mathrm{KIC}$ in plasma document effective absorption of the oral $\mathrm{L}-\left[1-{ }^{13} \mathrm{C}\right]$ leucine load (Fig. 4). The data in Figure 5 furthermore point at a rapid equilibration of ${ }^{13} \mathrm{C}$ label in the L-leucine and KIC pools. In none of these patients, however, could we detect an increase in the ${ }^{13} \mathrm{CO}_{2}$ exhalation.

Findings in variant MSUD. A total of nine $\mathrm{L}-\left[1-{ }^{13} \mathrm{C}\right]$ leucine loading tests were performed in eight patients with variant MSUD. Near-normal $(<250 \mu \mathrm{M})$ and clearly increased Lleucine plasma concentrations $(>500 \mu \mathrm{M})$ were present in four and five tests, respectively (Table 2).

The kinetics of L-leucine and KIC in plasma in the presence of near-normal and high concentrations of plasma L-leucine are 


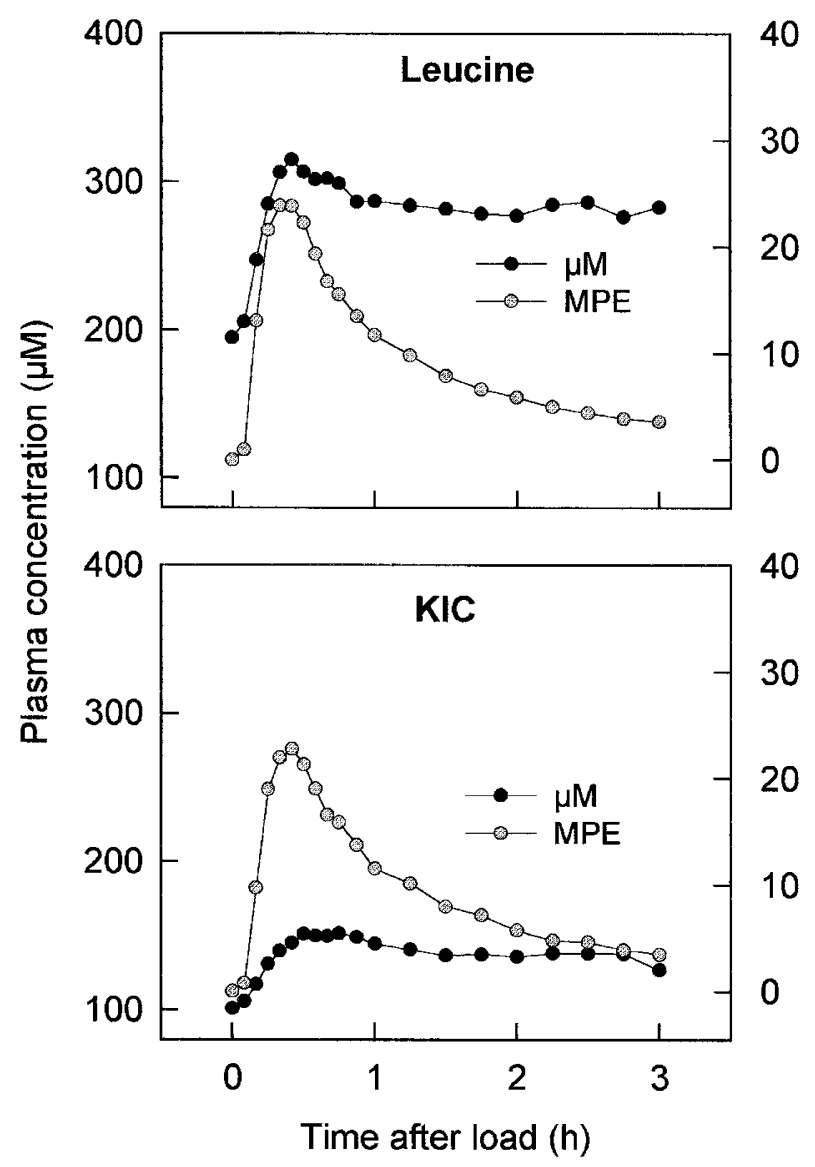

Figure 4. Time course of concentration and MPE in plasma L-leucine and KIC in a classical MSUD patient (M.M.) after an oral L- $\left[1-{ }^{13} \mathrm{C}\right]$ leucine load (38 $\mu \mathrm{mol} / \mathrm{kg}$ body wt).

exemplified in Figure 6. Initial increases of concentrations were similar to normal subjects (Fig. 3), subsequent decreases were similar to or somewhat more marked than in patients with classical MSUD (Fig. 4).

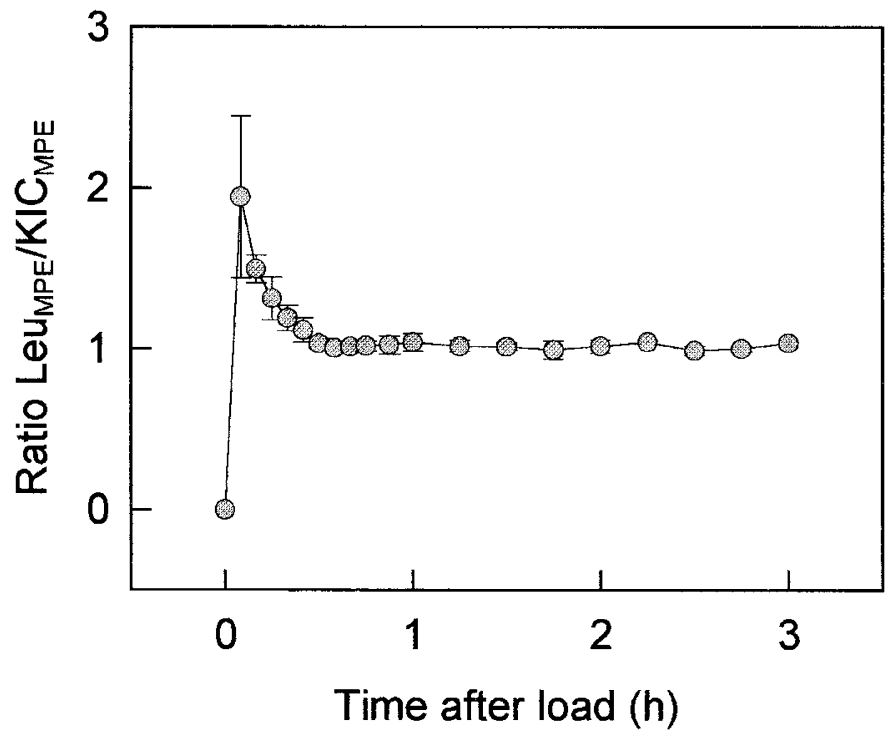

Figure 5. Time course of the relation of MPE in plasma L-leucine and KIC in classical MSUD patients after oral loading with $\mathrm{L}-\left[1-{ }^{13} \mathrm{C}\right]$ leucine $(38$ $\mu \mathrm{mol} / \mathrm{kg}$ body wt). Results are means $\pm \mathrm{SD}(n=4)$.
The levels and kinetics of decline of the ${ }^{13} \mathrm{C}$-enrichment were obviously dependent on the (plasma) pool size. At the lower plasma concentrations, maximal ${ }^{13} \mathrm{C}$-enrichments in $\mathrm{L}$ leucine and KIC amounted to $17.3 \pm 4.5$ (range, 10.6-20.7) MPE and $14.7 \pm 4.2(9.9-19.5)$ MPE $(n=4)$, respectively. At elevated plasma concentrations, the enrichment was decreased and amounted to $7.4 \pm 2.5(5.3-11.5) \mathrm{MPE}$ and $6.0 \pm 1.6$ (4.7-8.5) MPE $(n=5)$, respectively. The kinetics of decline in ${ }^{13} \mathrm{C}$-enrichment was similar to controls in patients with the lower L-leucine plasma concentrations but considerably delayed in the presence of high L-leucine pools (Fig. 6).

Each patient showed a significant increase of ${ }^{13} \mathrm{CO}_{2}$ exhalation after ingestion of $\mathrm{L}-\left[1-{ }^{13} \mathrm{C}\right]$ leucine (cf. Fig. 6). The rates of ${ }^{13} \mathrm{CO}_{2}$ exhalation were highly variable. Maximal rates ranged from 1.8 to $20.1 \mathrm{nmol} / \mathrm{min}$ per $\mathrm{kg}$ body wt. Related to the ingested ${ }^{13} \mathrm{C}$-dose, the cumulative extra ${ }^{13} \mathrm{CO}_{2}$ exhalation within the 3 -h test period in two severe variants (F.U., R.R.) was $<0.5 \%$, and between 2 and $7 \%$ in the milder variants.

Estimates of the residual WBLO (cf. Fig. 1, Table 3) are compiled in Figure 7. When compared with the mean WBLO in healthy subjects, WBLO in the severe variants was about $4 \%$ of control. In the milder variants, the WBLO was unexpectedly high and ranged from 19 to $86 \%$ of control.
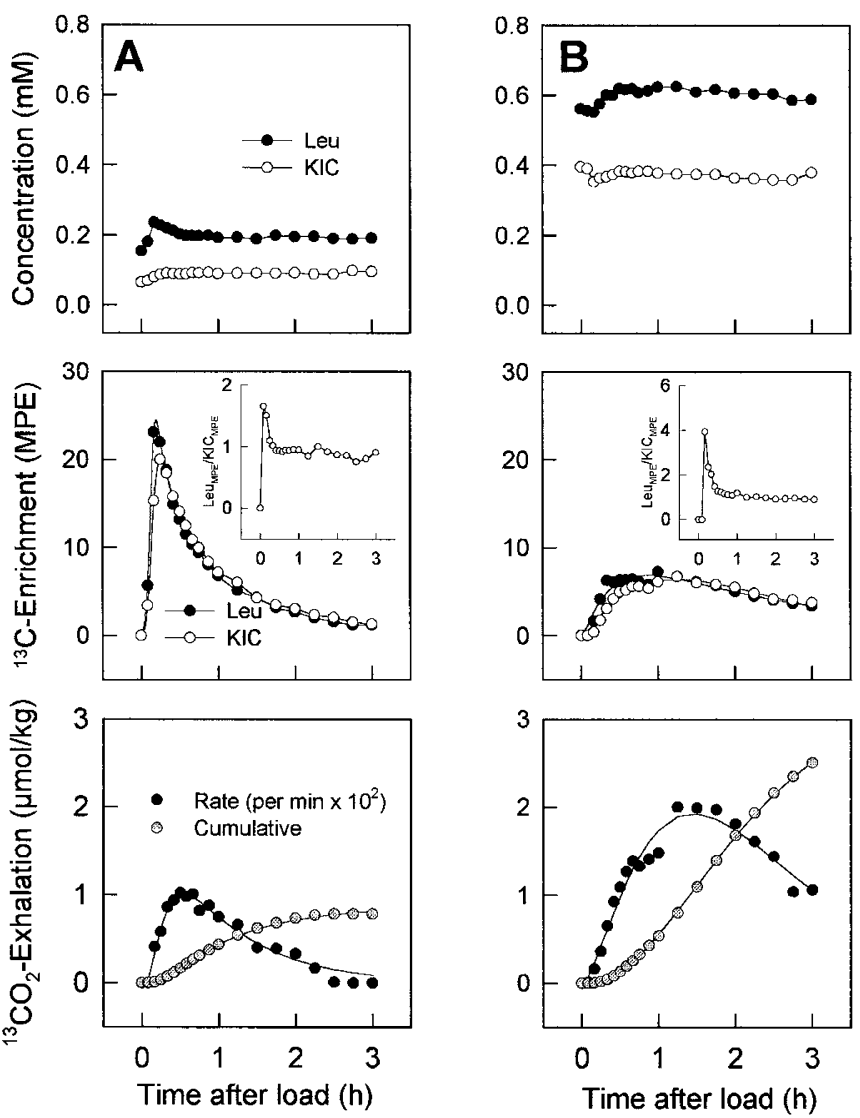

Figure 6. Time course of concentration and MPE in plasma L-leucine and KIC and of ${ }^{13} \mathrm{CO}_{2}$ exhalation over basal in two patients with variant form of MSUD after an oral L- $\left[1-{ }^{13} \mathrm{C}\right]$ leucine load (38 $\mu \mathrm{mol} / \mathrm{kg}$ body wt). Panels $A$ and $B$ show representative findings at low (patient M.S.) and high (patient L.F.) initial plasma-leucine/KIC concentrations, respectively (cf. Table 1). The lines were obtained by fitting procedures (see "Methods" for details). In the inserts, the relation of label enrichment in L-leucine and KIC are shown. 


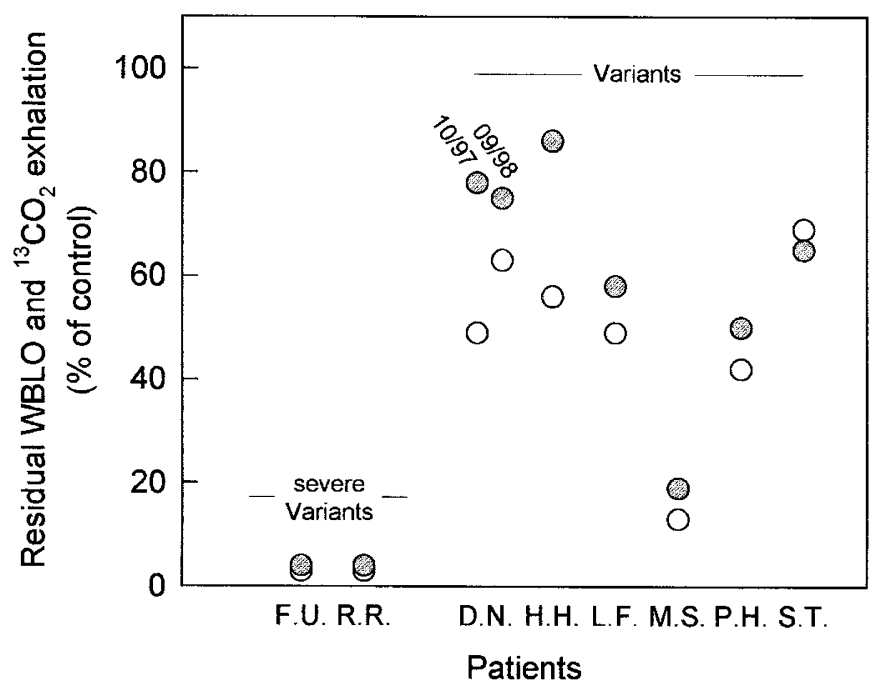

Figure 7. Total ${ }^{13} \mathrm{CO}_{2}$ exhalation (open circles) and residual whole-body L-leucine oxidation (filled circles) in patients with variant MSUD as assessed in oral L- $\left[1-{ }^{13} \mathrm{C}\right]$ leucine loading tests $(38 \mu \mathrm{mol} / \mathrm{kg}$ body wt). Patient D.N. underwent two loading tests at the dates indicated. In classical MSUD patients $(n=4)$, any L- $\left[1-{ }^{13} \mathrm{C}\right]$ leucine oxidation was too low to be detected. Data are related to the rates obtained in healthy subjects $(n=5$, control mean $\equiv 100 \%)$. See text for details.

Of particular interest are the findings in patient D.N., who agreed to be studied twice. This patient had high BCAA and BCOA plasma concentrations at the first occasion but only moderately elevated concentrations in the second test (Table 2). Although quite different ${ }^{13} \mathrm{C}$-labeling kinetics in exhaled $\mathrm{CO}_{2}$ and plasma $\mathrm{KIC}$ were observed in each test (data not shown), estimates of the residual WBLO were practically identical and amounted to 78 and $75 \%$ of control, respectively.

\section{DISCUSSION}

Pretest dietary stabilization. In stable isotope turnover studies comparing WBLO in MSUD patients and healthy subjects, the patients would ideally have normal and essentially constant pools of BCAA and BCOA because (a) elevated metabolite pools increase the dilution of label and reduce the sensitivity of the test, and (b) variability of pools within the experimental period might influence the tracer kinetics and interfere with the evaluation $(9,10,17)$.

However, the metabolic block in MSUD makes adjustment of normal plasma concentrations complicated. BCAA and BCOA can increase rapidly within hours due to BCAA intake or endogenous release during catabolic situations. Diminuation of elevated plasma concentrations is slow and may take days or weeks, even under intensified therapy $(6,9,18-22)$. Stable and normal BCAA and BCOA concentrations may be predetermined with sufficient reliability, when patients are hospitalized and maintained under strict dietary control. The latter, however, would not have been tolerated by the patients and their parents. Therefore, we decided to perform our studies when the patients were well and in an overall stable metabolic condition.

In our first patient with classical MSUD, the plasma concentration of L-leucine plus KIC rose by about $300 \mu \mathrm{M}$ after an overnight fast. This is consistent with the release of L-leucine from protein turnover in postabsorptive subjects $[10-20$ $\mu \mathrm{mol} / \mathrm{h}$ per kg body wt $(5,6,9)]$. Our effort to counteract the nocturnal catabolism in classical MSUD by continuous infusion of D-glucose was unsuccessful, however. This was somewhat unexpected because D-glucose is used in the treatment of (imminent) metabolic derangements (19). Most likely, anabolic effects of D-glucose had been overcome by the stress imposed on our patients by hospitalization and treatment (23). Stabilization of plasma BCAA in the MSUD patients was finally achieved by the following provisions that reduced the psychological and catabolic stress: (a) training on test procedures, (b) habitual environment, (c) presence of parents and attending pediatricians, and (d) additional intake of carbohydrate-rich meals.

Methodological concerns. The early-morning test meal induced some increase in ${ }^{13} \mathrm{CO}_{2}$ exhalation, which declined during the time period assigned to the $\mathrm{L}-\left[1-{ }^{13} \mathrm{C}\right]$ leucine loading test. Presumably, this led to some underestimation of ${ }^{13} \mathrm{CO}_{2}$ formation from $\mathrm{L}-\left[1-{ }^{13} \mathrm{C}\right]$ leucine, because the ${ }^{13} \mathrm{CO}_{2}$ exhalation collected just before load was taken as a basal value. In patients with classical MSUD, it can thus not be excluded that subtle $\mathrm{L}-\left[1-{ }^{13} \mathrm{C}\right]$ leucine-dependent changes of ${ }^{13} \mathrm{CO}_{2}$ exhalation might have been obscured. The data in Figure 2 indicate that total $\mathrm{L}-\left[1-{ }^{13} \mathrm{C}\right]$ leucine-derived ${ }^{13} \mathrm{CO}_{2}$ exhalation might have been underestimated by up to $0.3 \mu \mathrm{mol} / \mathrm{kg}$ body wt in the subjects under study. Therefore, the residual WBLO in the variant patients, as depicted in Figure 7, might be underestimated by up to about $5 \%$ by this effect alone. In a number of patients, however, a meal effect was likely to be balanced by adverse effects of their high L-leucine plasma concentrations, as will be discussed below.

Assessment of WBLO in classical MSUD. In the four patients under study, there was no detectable $\mathrm{L}-\left[1-{ }^{13} \mathrm{C}\right]$ leucineinduced increase in ${ }^{13} \mathrm{CO}_{2}$ exhalation. Three of the patients with classical MSUD exhibited near-normal L-leucine plasma concentrations, and their ${ }^{13} \mathrm{C}$-label enrichment in $\mathrm{KIC}$ was in the normal range. According to previous considerations (10), the sensitivity for detection of a residual WBLO in these patients was about $3-5 \%$ of control. Thus, the present findings supplement previous observations and corroborate our presumption that $\mathrm{L}$-leucine oxidation in classical MSUD is too low to be measured in a feasible way by the present procedure (10).

Perhaps, an increase in ${ }^{13} \mathrm{CO}_{2}$ exhalation may become measurable using a (considerably) increased $\mathrm{L}-\left[1-{ }^{13} \mathrm{C}\right]$ leucine bolus. This implies the risk, however, that plasma L-leucine may exceed the potentially (neuro)toxic level of $800-1000 \mu \mathrm{M}$ [Table 1, patients H.H. and S.T. (2)]. We decided not to apply larger $\mathrm{L}-\left[1-{ }^{13} \mathrm{C}\right]$ leucine loading doses to firmly exclude any noxious effects.

Significance of WBLO estimates in variant MSUD. So far, only one study has addressed in vivo L-leucine oxidation in variant MSUD. L- $\left[1-{ }^{13} \mathrm{C}\right]$ Leucine bolus tests were performed and WBLO deduced from the ${ }^{13} \mathrm{CO}_{2}$ exhalation within $6 \mathrm{~h}(8)$. Interpretation of ${ }^{13} \mathrm{CO}_{2}$ exhalation rates in terms of WBLO and effects of treatment is questionable, however, unless dilution of the ${ }^{13} \mathrm{C}$-label is taken into account. For example, in that study, a patient was classified thiamine-responsive because her ${ }^{13} \mathrm{CO}_{2}$ exhalation increased from 0 to $3.6 \%$ of the ${ }^{13} \mathrm{C}$-dose applied 
after $1 \mathrm{mo}$ of thiamine treatment. The basal L-leucine plasma concentrations were 1200 and $400 \mu \mathrm{M}$ at the first and second tests, respectively. Thus, the increase in ${ }^{13} \mathrm{CO}_{2}$ release can easily be explained as well by the far lower ${ }^{13} \mathrm{C}$-label dilution in the second test.

In our patients, the clinical severity covered the whole range from severe to mild variant forms. Therefore, the present results seem to be rather representative for variant MSUD. In all patients, ${ }^{13} \mathrm{CO}_{2}$ exhalation increased significantly after the $\mathrm{L}-\left[1-{ }^{13} \mathrm{C}\right]$ leucine load. The basal (initial) $\mathrm{L}$-leucine concentrations, however, were highly variable and not related to the clinical severity of the disease. This is clearly documented in the two tests of the mild variant D.N., who had quite different BCAA plasma concentrations on each occasion (Table 2).

Due to a considerable interindividual variability, it is impossible, however, to predict dilution of the ${ }^{13} \mathrm{C}$-label with sufficient accuracy on the basis of initial L-leucine and KIC plasma concentrations. We here suggest a relatively rapid and convenient noncompartmental procedure to estimate the residual WBLO in variant MSUD patients, which takes into account the dilution of ${ }^{13} \mathrm{C}$-label. Theoretically, compartmental analysis, as incidentally used for evaluation of in vivo L-leucine oxidation in healthy subjects $(13,24)$, could also be applied for evaluation. With the present state of knowledge, no reliable assessment of the possible systematic errors inherent in the oral $\mathrm{L}-\left[1-{ }^{13} \mathrm{C}\right]$ leucine loading test can be made in MSUD, which might be comparable to the insights into leucine/KIC metabolism of healthy subjects provided by compartmental modeling approaches.

In variant MSUD, our estimates for residual WBLO ranged from 4 to $86 \%$ of control. However, as the L-leucine/KIC concentrations in patients were highly variable, the question arises whether and to what extent residual WBLO in patients with different L-leucine/KIC pools (concentrations) might actually reflect the residual total substrate flux through the BCOA-DH in vivo. Four patients had near-normal L-leucine plasma concentrations $(<250 \mu \mathrm{M})$ and also near-normal relations of the branched-chain compounds in plasma. In these patients, the relation of residual WBLO to residual total metabolic flux through the BCOA-DH in situ can be expected to be largely comparable to the conditions in controls.

Five variant patients had clearly increased L-leucine plasma concentrations $(>500 \mu \mathrm{M})$ and the relation of branched-chain substrates was changed. The mean relation of the BCAA/ BCOA substrate pairs L-leucine/KIC, L-valine/3-methyl-2oxobutanoate, and L-isoleucine/3-methyl-2-oxopentanoate in the two severe variants (F.U., R.R.) amounted to 10:3:4 and in three milder variants (D.N., L.F., S.T.) to 10:7:4 compared with a relation of 10:17:5 in healthy subjects. Thus, the contribution of the L-leucine/KIC pair to total branched-chain substrate supply in plasma was about 60 and $45 \%$, in the severe variants and milder variants, respectively, compared with $30 \%$ in controls.

In healthy subjects, L-leucine/KIC oxidation accounts for about $50 \%$ of the in vivo metabolic flux through the BCOA-DH (13). In accordance, model experiments with $1-{ }^{14} \mathrm{C}$-labeled substrates and cultured skin fibroblasts from controls and variant MSUD patients in our laboratory showed that L-
leucine/KIC oxidation accounted for $50 \%$ of the total metabolic flux with normal relations of branched-chain compounds in the incubation medium (both at normal and increased total substrate concentrations). When the portion of L-leucine/KIC in the medium was increased to $60 \%$ of the total substrate, the relation of L-leucine/KIC oxidation to total branched-chain substrate oxidation was enhanced to about $70 \%(25,26)$. There are indications that similar substrate interaction effects occur in vivo (27).

The latter findings indicate that L-leucine/KIC oxidation in the two severe and the three milder variants exhibiting high plasma concentrations may have accounted for a higher contribution $(60-70 \%)$ to whole-body substrate flux through the BCOA-DH than in controls. Thus, WBLO in these patients would not be strictly comparable to the WBLO in controls. Estimates based on the interpolation of the in vitro data suggest that an overestimation of the residual WBLO due to elevated L-leucine/KIC concentrations should be $<2 \%$ in the severe variants and $<10 \%$ in the milder variants.

Taken together, the foregoing considerations indicate that neither meal-induced changes in ${ }^{13} \mathrm{CO}_{2}$ exhalation nor the variability in plasma $\mathrm{BCAA} / \mathrm{BCOA}$ relations interfered grossly with the present estimation of residual WBLO and further suggest the residual WBLO to be rather representative for whole-body metabolic flux through the BCOA-DH in our variant MSUD patients.

With the exception of the severe variants, the estimated residual WBLO in the patients was astonishingly high, about 2to 5-fold higher than the (available) residual BCOA-DH activity in the patients' skin fibroblasts. This apparent discrepancy might be explained by the fact that the BCOA-DH is fully activated (dephosphorylated) in incubated cells (11). Thus, measurements in vitro actually yield a measure of (residual) total enzyme capacity, whereas the WBLO is determined by the (residual) amount of active complex in vivo.

In most human tissues, the BCOA-DH is primarily in the inactive, phosphorylated state. On the basis of reported data (28-32), it can be estimated that approximately $5 \%$ of wholebody BCOA-DH may be active under normal conditions, and this amount is responsible for the WBLO in our healthy subjects (10). The comparatively high residual WBLO in the variant patients could, in principle, be due to the following different mechanisms: (a) differentially increased expression of BCOA-DH in tissues other than skin fibroblasts, (b) altered kinetic properties (i.e. increase of the Michaelis constant), or (c) an increase in the mean (whole-body) activity state of the mutant enzyme complex. Whether and to what extent these mechanisms may contribute to WBLO in an individual patient remains to be determined.

Reproducibility. In patient D.N., undergoing two tests under quite different metabolic situations, residual WBLO estimates could be determined reproducibly. With respect to the significant intraindividual variability of L-leucine oxidation observed in two healthy adults [coefficients of variation of WBLO estimates: 36\% (5 tests) and 49\% (4 tests); recalculated from previous experiments (10)], however, there was a striking agreement of the residual WBLO estimates in both tests. The latter suggests that variability of WBLO in MSUD patients 
may be generally lower than in controls and this may be explained by the fact that the impairment in BCOA degradation in MSUD reduces considerably the overall flexibility and adaptability of BCAA metabolism, even in mild variants.

\section{CONCLUSION}

The present study indicates that residual L-leucine oxidation in vivo can be assessed in variant MSUD by invasive L-[1$\left.{ }^{13} \mathrm{C}\right]$ leucine bolus tests. Comparatively high residual WBLO were observed in variant MSUD. It remains to be elucidated whether this might be achieved, e.g. by an increased activity state of the BCOA-DH in situ. The latter could provide a reasonable explanation for the generally rather unsatisfying correlation between the clinical severity and the residual BCOA-DH capacity as assessed in the patients' cells in vitro.

Acknowledgments. This study was generously supported by the following colleagues: Herbert Brösicke and Eberhardt Mönch, Berlin, Germany; Dorothea Leupold, Ulm, Germany; Rudolf Mallmann, Essen, Germany; Klaus Mohnike and Irmgard Starke, Magdeburg, Germany; Helmut Niederhoff, Freiburg, Germany; Barbara Pleçko, Graz, Austria; Jean-Marie Saudubray, Paris, France; and Jörg Seidel, Jena, Germany.

\section{REFERENCES}

1. Online Mendelian Inheritance in Man (OMIM) 2000 National Center for Biotech nology Information Web site. Available at: http:/www.ncbi.nlm.nih.gov/omim

2. Chuang DT, Shih VE 1995 Disorders of branched chain amino acid and keto acid metabolism. In: Scriver CR, Beaudet AL, Sly WS, Valle D (eds) The Metabolic and Molecular Bases of Inherited Disease. McGraw-Hill, New York, pp 1239-1278

3. Scriver CR, Clow CL, George HG 1985 So-called thiamin-responsive maple syrup urine disease: 15-year follow-up of the original patient. J Pediatr 107:763-765

4. Collins JE, Umpleby AM, Boroujerdi MA, Leonard JV, Sonksen PH 1987 Effect of insulin on leucine kinetics in maple syrup urine disease. Pediatr Res 21:10-13

5. Thompson GN, Bresson JL, Pacy PJ, Bonnefont JP, Walter JH, Leonard JV, Saudubray JM, Halliday D 1990 Protein and leucine metabolism in maple syrup urine disease. Am J Physiol 258:E654-E660

6. Thompson GN, Francis DEM, Halliday D 1991 Acute illness in maple syrup urine disease: dynamics of protein metabolism and implications for management. J Pediatr 119:35-41

7. Thompson GN, Walter JH, Leonard JV, Halliday D 1990 In vivo enzyme activity in inborn errors of metabolism. Metabolism 39:799-807

8. Elsas II LJ, Ellerine NP, Klein PD 1993 Practical method to estimate whole body leucine oxidation in maple syrup urine disease. Pediatr Res 33:445-451

9. Schadewaldt P, Wendel U 1997 Metabolism of branched-chain amino acids in maple syrup urine disease. Eur J Pediatr 156(suppl 1):S62-S66

10. Schadewaldt P, Bodner A, Brösicke H, Hammen H-W, Wendel U 1998 Assessment of whole body L-leucine oxidation by non-invasive $\mathrm{L}_{-}\left[1-{ }^{13} \mathrm{C}\right]$ leucine breath tests: reappraisal in patients with maple syrup urine disease, obligate heterozygotes, and healthy subjects. Pediatr Res 43:592-600

11. Schadewaldt P, Beck K, Wendel U 1989 Analysis of maple syrup urine disease in cell culture: use of substrates. Clin Chim Acta 184:47-56

12. Schadewaldt $P$, Bodner-Leidecker A, Hammen H-W, Wendel U 1999 Significance of L-alloisoleucine in plasma for diagnosis of maple syrup urine disease. Clin Chem 45:1734-1740

13. Bodner A, Hammen H-W, Renn W, Wendel U, Schadewaldt P 1997 Branched-chain L-amino acid oxidation in overnight fasted human subjects. Isotopes Environ Health Stud 33:189-196

14. Wolfe RR 1992 Radioactive and Stable Isotope Tracers in Biomedicine: Principles and Practice of Kinetic Analysis. Wiley-Liss, New York, pp 230-232

15. Schwenk W, Beaufrére B, Haymond MW 1985 Use of reciprocal pool specific activity to model leucine metabolism in humans. Am J Physiol 249:E646-E650

16. Frereday A, Gibson NR, Cox M, Pacy PJ, Millward DJ 1997 Protein requirements and ageing: metabolic demand and efficiency of utilization. Brit J Nutr 77:685-702

17. Bier DM 1989 Intrinsically difficult problems: the kinetics of body proteins and amino acids in man. Diabetes Metab Rev 5:111-132

18. Snyderman SE, Norton PM, Roitman E, Holt Jr LE 1964 Maple syrup urine disease, with particular reference to dietotherapy. Pediatrics 34:454-462

19. Wendel U, Langenbeck U, Lombeck I, Bremer HJ 1982 Maple syrup urine diseasetherapeutic use of insulin in catabolic states. Eur J Pediatr 139:172-175

20. Wendel U 1984 Acute and long-term treatment of children with maple syrup urine disease. In: Adibi SA, Fekl W, Langenbeck U, Schauder P (eds) Branched Chain Amino and Keto Acids in Health and Disease. Karger, Basel, pp 335-347

21. Shigematsu Y, Kikuchi K, Momoi T, Sudo M, Kikawa Y, Nosaka K, Kuriyama M, Haruki S, Sanada K, Hamano M, Suzuki Y 1983 Organic acids and branched-chain amino acids in body fluids before and after multiple exchange transfusion in maple syrup urine disease. J Inherit Metab Dis 6:183-189

22. Berry GT, Heidenreich R, Kaplan P, Levine F, Mazur A, Palmieri MJ, Yudkoff M, Segal S 1991 Branched-chain amino acid free parenteral nutrition in the treatment of acute metabolic decompensation in patients with maple syrup urine disease. $\mathrm{N}$ Engl J Med 324:175-179

23. Brillon DJ, Zheng B, Campbell RG, Matthews D 1995 Effect of cortisol on energy expenditure and amino acid metabolism in humans. Am J Physiol 268:E501-E513

24. Cobelli C, Saccomani MO, Tessari P, Biolo G, Luzi L, Matthews DE 1991 Compartmental model of leucine kinetics in humans. Am J Physiol 262:E539-E550

25. Schadewaldt P, Wendel U, Bodner A 1998 On the relation of leucine oxidation to total metabolic flux through the branched-chain 2-oxo acid dehydrogenase complex (BCOA-DH) in situ. J Inherit Metab Dis 21(suppl 2):18(abstr)

26. Bodner-Leidecker A 2000 Stoffwechsel verzweigtkettiger L-Aminosäuren bei Ahronsirupkrankheit. Thesis, Universität Düsseldorf, Düsseldorf, Germany, pp 129-153

27. Block KP 1989 Interactions among leucine, isoleucine and valine with special reference to branched-chain amino acid antagonism. In: Friedman M (ed) Absorption and Utilization of Amino Acids. CRC Press, Boca Raton, FL, pp 229-244

28. Suryawan A, Hawes JW, Harris RA, Shimomura Y, Jenkins AE, Hutson SM 1998 A molecular model of human branched-chain amino acid metabolism. Am J Clin Nutr 68:72-81

29. van Hall G, Saltin B, van der Vusse GJ, Söderlund K, Wagenmakers AJM 1995 Deamination of amino acids as source for ammonia production in human skeletal muscle during prolonged exercise. J Physiol 489:251-261

30. Wagenmakers AJM, Brookes JH, Coakley JF, Reilly T, Edwards RHT 1989 Exerciseinduced activation of the branched-chain 2-oxo acid dehydrogenase in human muscle. Eur J Appl Physiol 59:159-167

31. Jackman ML, Gibala MJ, Hultman E, Graham TE 1997 Nutritional status affects branched-chain oxoacid dehydrogenase activity during exercise in humans. Am J Physiol 272:E233-E238

32. Bowtell JL, Leese GP, Smith K, Watt PW, Nevill A, Rooyackers O, Wagenmakers AJM, Rennie MJ 1998 Modulation of whole body protein metabolism, during and after exercise, by variation of dietary protein. J Appl Physiol 85:1744-1752 